UDC: 811.111:37 https://doi.org/10.22190/JTESAP2002123T

\title{
PRINCIPLED PRAGMATISM AND EXPERIENTIAL LEARNING: TWO FACETS OF CONSTRUCTIVISM IN ESP
}

\author{
Oleg B. Tarnopolsky ${ }^{1}$, Svitlana P. Kozhushko ${ }^{2}$ \\ ${ }^{1}$ Department of Applied Linguistics and Methods in Foreign Language Teaching at Alfred Nobel University, \\ Ukraine \\ E-mail: otarnopolsky@ukr.net \\ ${ }^{2}$ Department of International Tourism, Hotel and Restaurant Business, and Language Training at Alfred Nobel \\ University, Ukraine \\ E-mail: lana@duan.edu.ua
}

\begin{abstract}
The article discusses two approaches that are considered to be the most promising ones in today's teaching of English for Specific Purposes (ESP). The two approaches in question are Kumaravadivelu's principled pragmatic approach and the experiential learning approach. It is shown that they both help to unify into one single new paradigm the three leading paradigms in modern ESP teaching: content-based instruction, English immersion, and culture-specific target language learning. After defining each of the two approaches in ESP courses at tertiary schools, the paper proceeds to prove the authors' leading idea that both principled pragmatism and experiential learning are a perfect match embodying two facets of a broader pedagogical approach that is applicable not only when teaching ESP (and teaching foreign languages in general) but also when teaching other disciplines, especially at the tertiary school level. This broader pedagogical approach is constructivism, which provides students with opportunities for 'constructing' their own knowledge and skills through practical experience in real-life or modeled activities. In this case, students acquire their knowledge and skills (including skills of communicating in the target language) as a by-product of their real-life or modeled activities, thus internalizing (appropriating) the knowledge and skills and not just learning them. The peculiarities of constructivism in ESP courses are discussed, and the guidelines are given for the practical implementation of the principled pragmatic approach through experiential learning activities in the framework of the fully constructivist ESP course (in what concerns its theoretical and methodological foundations).
\end{abstract}

Key words: tertiary professional education, paradigms in ESP teaching and learning, principled pragmatic approach, experiential learning approach, constructivism in language teaching, contentbased instruction, English immersion, culture-specific target language learning.

\section{INTRODUCTION}

English for Specific Purposes (ESP) - embraces all cases of teaching that language as a second/foreign one when it is taught and learned for professional communication (Robinson, 1991). A great variety of specific professional sublanguages are included into ESP: from English for Science and Technology, English for Medicine, etc. to Business English. All these varieties are united by common approaches to teaching them in such educational contexts as professional tertiary educational institutions, commercial ESP courses, and some other organizational forms of instruction. Such common approaches can be classified into three principal paradigms that are prevalent in today's ESP training at tertiary professional (non-linguistic) schools in Ukraine. 
Before speaking about the three paradigms, it should be noted that in fact there are many more than three. For instance, the traditional foreign language teaching approach based on the obsolete grammar-translation method is also a paradigm, sometimes used even now and even in ESP courses (when learning is mostly reduced to memorizing terminology, analyzing professional texts from the point of view of their grammar, logical structure, and translating those texts as a means of checking their understanding by students). But these types of paradigm will be neither considered nor even mentioned in this article because, being mostly obsolete and mostly proven to be ineffective in teaching practice, they have become marginal and are used only by those ESP teachers who 'know no better'. The three paradigms that were mentioned in the preceding paragraph are not only the cutting-edge ones in today's ESP teaching; they are also the mainstream ones, i.e. those that are considered to be the most efficient and, therefore the most frequently used by practical ESP teachers who strive to achieve the highest possible level of efficiency in their teaching. These three paradigms include:

1. Content-based instruction;

2. English immersion in courses of professional disciplines;

2. Culture-specific ESP teaching, or the intercultural approach.

As we begin to consider the three indicated paradigms, it should be remarked that all three of them have their roots in the communicative approach to language teaching and learning Communicative Language Learning (CLL) but with a strong professional bias in the CLL environment because ESP is taught for being used in professional communication, learned through that professional communication, and acquired using the means of professional communication. Such a CLL foundation exists even in the last, intercultural, or culture-specific, paradigm, though its adherents sometimes deny that - the issue that will be analyzed further. It should also be noted that the three language teaching paradigms above are meant for teaching target language professional communication only when the students have already reached B1+/B2 level (Council of Europe, 2001) in their command of General English.

Content-based instruction (Brinton, Snow, Wesche, 1989; Stoller, 2007) is a way of integrating teaching the language for professional communication with professional subject matter, e.g. the subject matter of professional disciplines taught to tertiary students of Science and Technology, Medicine, Economics and Business, or any other non-linguistic major. As a result, in the course of ESP, students are learning the basics of their future profession through the medium of the target language, with their attention mostly focused on the professional content supplied to them (in a somewhat simplified form) in the language to be acquired for professional use. Thanks to that, the language acquisition is frequently involuntary, or subconscious, - achieved in the process of focused learning of the content matter material taught in the target language. This subconscious language acquisition greatly facilitates achieving the desired linguistic and communicative learning outcomes of the ESP teaching (Tarnopolsky, 2012). What is no less important is the fact that in the content-based ESP course at tertiary educational institutions the gap between the language studies and the studies of the learners' majoring disciplines is eliminated, so that the students' entire professional tuition is harmoniously 'welded' into sustained professional training that includes an organic language constituent. Such a constituent ensures opportunities for using the acquired professional knowledge and skills not only locally (in the students' home country) but internationally - thus making the international labor market accessible to university graduates. 
Immersion programs in English or other languages (Johnson, Swain, 1997) are programs of teaching non-linguistic disciplines, like history, physics, or any professional disciplines from the secondary or tertiary school curriculum in the target language instead of the learners' mother tongue (L1). Immersion programs may be of different levels of difficulty depending on how much attention in them is paid to the target language. If some language focusing or even help from L1 is possible in preliminary or partial immersion, in total immersion the target language is used as a tool only - with minimal (only rarely applicable) focusing on it while the students' L1 is totally excluded (Tarnopolsky, Momot, Kozhushko, et al., 2008). Thus, when English immersion is introduced into tertiary professional education, it is the highest form of involuntary target language learning when students' attention is almost completely focused on the subject matter of their majoring disciplines taught in English, while the language is being acquired mostly subconsciously through sustained communication in that language in the teaching/learning process.

Culture-specific language teaching or the intercultural approach (Byram, 1997) entered ESP several decades ago with the realization of the fact that adequate and successful intercultural professional communication depends not only, and even not so much, on the command of the language used for that communication (in most cases English) as on the communicators' abilities to avoid and prevent cultural clashes and incompatibilities in their intercourse. Such incompatibilities are much more harmful for professional communication than some of the communicators' deficiencies in the command of the international language used for that intercourse (Ferradas, 2010). This is especially true of international and intercultural business communication; so the intercultural approach has spread more widely in Business English teaching and learning than in other kinds of ESP. The spread and popularity of the intercultural approach has even led to statements that this approach is bound to replace the CLL approach as a new paradigm replaces the obsolete one (Burkert, Mumford, \& Lackman, 2010). In reality, such beliefs are a result of simple misunderstanding because intercultural teaching/learning is in charge of the teaching/learning content (what to teach and learn) while CLL is in charge of the teaching and learning methods (how to teach and learn the content to be taught). Moreover, the intercultural approach and CLL are ideally compatible since both the language and the culture in ESP (like in any other English course) are taught for better professional communication in English (there is no other reason to teach them), and this is the area of responsibility of CLL, while such communication can become fully adequate only if students master all its cultural peculiarities, and that is the area of responsibility of the intercultural approach (Tarnopolsky, 2011). Thus, the intercultural approach is absolutely indispensable in today's ESP teaching and learning but it can 'work' efficiently only if it is implemented through the CLL approach.

In general, it can be safely asserted that all the three paradigms discussed above are necessary for effective ESP teaching and learning but only if used in unison and without opposing and contradicting each other. But this requires a new paradigm which harmoniously unites the first three. Theoretically and practically substantiating that paradigm is the goal of this article, and the foundation of the new paradigm is seen as being rooted in principled pragmatism, while its practical implementation is seen to lie within the framework of experiential learning - both approaches embodying the innovative constructivist paradigm in ESP. 


\section{PRINCIPLED PRAGMATISM IN ESP AS THE BASIS OF A NEW UNIFIED PARADIGM IN ITS TEACHING AND LEARNING}

Principled pragmatism, whose theory has been developed by Kumaravadivelu (2001; 2003), this theory being proclaimed by the author as heralding the new post-method era in teaching English as a second or foreign language, is probably the best "construction site" on which to erect the new unified ESP teaching and learning paradigm in question. The reason is due to the fact that principled pragmatism is based on the assumption that there is no best single method of language teaching and such a universal method is in principle impossible. However, all the existing methods can be used together by uniting those of their features that are best suited to some specific conditions of language teaching and learning. Which of those features to unite and how to unite them is for the practical teacher (who must, according to Kumavaradivelu, become a teacher-researcher) to decide. Thus, the principled pragmatic theory of language teaching and learning is from its very inception aimed at the pragmatic unification of different approaches, taking the best and the most suitable from each of them - which is exactly what is required for creating the new ESP paradigm spoken about in the Introduction to this article.

It may be said that Kumaravadivelu's theory advocates eclecticism in language teaching and learning, but that eclecticism is well-grounded (Tarnopolsky, 2018) since, uniting different approaches into one single whole, the teacher-researcher has no choice but to follow several principles because the new unified whole is required to incorporate each of them in order to be recognized as adequate and suitable for pedagogical practice. These principles developed by Kumaravadivelu include:

1. Maximizing learning opportunities;

2. Minimizing perceptual mismatches;

3. Facilitating negotiated interaction;

4. Promoting learner autonomy;

5. Fostering language awareness;

6. Activating intuitive heuristics;

7. Contextualizing linguistic input;

8. Integrating language skills;

9. Ensuring social relevance;

10. Raising cultural consciousness.

There is nothing in content-based instruction, English immersion, or culture-specific language teaching paradigms that would oppose or contradict the ten principles listed above. All of them were specifically designed to maximize ESP learning opportunities and are to a great extent built on students' autonomous in and out of class learning activities (such as autonomous search for professional or cultural information in the target language). This autonomy also minimizes perceptual mismatches, i.e. misunderstandings between the teacher, on the one hand, and the students, on the other. The fact that all three approaches by their very nature presuppose that learners mostly work in collaboration with each other negotiating in the target language in the process of their interaction (see the third principle above) and are largely autonomous in their learning activities turns the teacher into a facilitator (Rogers, 1987), not so much teaching as facilitating learning - which leaves few chances for the emergence of perceptual mismatches.

None of the three paradigms is averse either to fostering language awareness or to promoting intercultural consciousness (the $5^{\text {th }}$ and $10^{\text {th }}$ of Kumaravadivelu's principles). 
Content-based ESP instruction is always used in an ESP language course, and in any such course some kind of language focusing to raise learners' consciousness of language phenomena is inevitable (Fotos, 1994; Rutherford, 1987). The same concerns the early forms of English immersion (preliminary and partially - see Tarnopolsky, Momot, Kozhushko, et al., 2008). Even in total immersion this may sometimes be required, although only episodically, due to the high level of students' command of the language when such an immersion is introduced in the final stages of learners' university studies - see the Introduction. In the intercultural approach, language focusing is also inevitable when dealing with culture-specific verbal forms of communication (e.g., how to object politely to other participants in some professional discussion). As to promoting intercultural consciousness, the intercultural approach is totally devoted to it, while both in content-based instruction and in English immersion teaching the culture-specific norms of professional communication is an absolute requirement (e.g., teaching the cultural norms of conducting business negotiations in English in intercultural environments).

By the very fact that all three paradigms under discussion are ESP teaching and learning oriented, they cannot fail to contextualize the linguistic input (place it in the context of students' future profession) and provide for its social relevance (teaching the language for the needs of learners' future professional activities). Thus, the requirements of Kumaravadivelu's $7^{\text {th }}$ and the $9^{\text {th }}$ principles are fully satisfied.

In the same way, content-based instruction, English immersion, and culture-specific language learning are and have always been aimed at teaching all four basic language/communication skills: speaking, listening, reading, and writing, since they are all in equal demand when using English for professional purposes. For instance, when being taught ESP using the intercultural approach, students should be required to learn not only to speak and write following the cultural norms dominant in the target lingua-socio-cultural community, they should also distinguish those norms when listening and reading and act accordingly in response to what was heard or read. This means designing the tuition process in full accordance with Kumaravadivelu's $8^{\text {th }}$ principle, the integration of language skills.

Finally, the $6^{\text {th }}$ principle of Kumaravadivelu, activation of intuitive heuristics is naturally and even automatically followed in all three approaches under consideration because all three of them, as has already been said, are rooted in the communicative approach, so that students constantly take part in communication practice. And communication practice cannot fail to activate intuitive heuristics required for solving all the non-algorithmic communicative tasks.

Therefore, it can be safely concluded that principled pragmatism is an excellent foundation for combining all three paradigms in question into a single, organically 'welded' new paradigm because they fully meet each of the 10 principled pragmatic principles. It remains to find the practical ways and means of such 'welding' which can be found in experiential learning.

\section{EXPERIENTIAL LEARNING AS A PRACTICAL WAY OF DEVELOPING A NEW UNIFIED PARADIGM OF ESP TEACHING AND LEARNING}

Experiential learning, or learning from practical experience (Kolb, 1984), came to the field of language teaching much later than it did in the teaching of other disciplines, especially at tertiary educational institutions. In teaching foreign languages for 
professional communication (ESP), experiential learning means such an organization of the teaching/learning process which gives opportunities for continuously modeling the future specialists' professional activities in their language acquisition activities, so that the latter model professional communication. The most important issue is that students communicate on professional matters in the target language and not in their L1, and it is in the process of that communication that that the target language is acquired practically involuntarily and often even subconsciously (Kohonen, Jaatinen, Kaikkonen, Lehtovaara, 2014; Tarnopolsky, 2012). For instance, if students of Business and Economics in their class of English model, or simulate, a Board meeting of a company in English, it is an experiential learning activity in the course of which, if the activity is organized correctly, they subconsciously acquire different language material, communication formulas, and cultural norms of communicative behavior in the situations of business intercourse.

From the definition in the preceding paragraph it is clear that in ESP conditions experiential learning is always content-based and cannot be anything else but content-based because experiential learning activities, as has been said, model professional activities performed in the framework of professional target language communication. The example given above also shows how well-adapted experiential learning is to including cultural information into its activities with their implicit aim of ESP acquisition. In what concerns English immersion, all immersion teaching and learning is one non-stop experiential learning activity because it not only models the experience of acquiring professional knowledge and skills in the courses of tertiary students' majoring disciplines, it is such real acquisition itself, only achieved through the target language and not through learners' L1. Therefore, the experiential learning approach naturally and effortlessly combines in teaching and learning practice the three paradigms of modern ESP training discussed in this article: content-based instruction, English immersion, and culture-specific ESP teaching. That makes it an ideal approach to achieving the practical unification of the three paradigms into one single paradigm - the new (innovative) paradigm to substantiate which is the goal of this article.

However, the substantiation of such a paradigm needs to be not only practical but also theoretical, and since principled pragmatism was defined in the preceding part of the article as the theoretical foundation of the new unified paradigm, it should be proven that experiential learning practice fully meets (on the theoretical plane) the requirements of the principled pragmatic approach embodied in its 10 principles (Kumaravadivelu, 2003). For proving this, it should primarily be defined which kinds of learning activities are included into experiential learning.

In our preceding publications (Tarnopolsky, 2012; 2018) it was shown that experiential learning activities employed in teaching English for professional communication at nonlinguistic tertiary educational institutions include:

- role play and simulations,

- students' brainstorming, case studies, discussions,

- presentations,

- workshops,

- learning projects,

- writing professional essays, abstracts, summaries, etc. in the target language.

All those activities always require learners' autonomous search in- and out-of-class for information in the target language (mostly on professional Internet sites in English) and their processing of the information found through reading and listening with the aim of 
providing sufficient professional data required for doing all the profession-oriented creative learning tasks mentioned above. Therefore, this search and processing should also be included into the list of experiential learning activities as those which ensure the availability of the information potential for all the other activities. Besides, as it has already been said, English immersion can be considered as one multi-faceted experiential learning activity.

All such activities have a number of advantages that make them fully meet the 10 principles of principled pragmatism. First, these activities with no exceptions are quite intensive, highly varied, and require very active student participation. By this very fact they maximize learning opportunities (the $1^{\text {st }}$ of Kumaravadivelu's principles). Second, they are all interactive, since the absolute majority of them are performed in cooperation between students (for cooperative learning see Kessler, 1992), and learners working in such close cooperation have no choice but to negotiate while interacting to complete their learning tasks successfully (the $3^{\text {rd }}$ principle). Even the experiential writing activities, like composing professional essays, abstracts, summaries, etc., are interactive and cooperative because they are done by way of process writing (White, Arndt, 1991) - every piece to be written is first outlined in small group discussions (team writing) and every individual writing draft is peer-reviewed and peer-commented. The only more or less individual tasks are information search and information processing through reading and listening (though pair and small group work is quite possible in this case too), but they serve to collect the information required for more creative and totally interactive tasks. In what concerns English immersion as an experiential learning activity, this cannot avoid being interactive and cooperative because learning majoring subjects through the target language is more difficult than doing it by means of learners' L1. So, to compensate for additional difficulties, much closer negotiated interaction and cooperation among students and between the students and the teacher is required. All these forms of negotiated interaction and cooperation not only help to minimize perceptual mismatches (the $2^{\text {nd }}$ principle) but they also foster learners' autonomy (the $4^{\text {th }}$ principle) since students learn not so much from the teacher, as from their joint collaborative efforts in negotiated interaction required by experiential learning activities.

Actually, everything said in the preceding paragraph reproduces almost word-for-word what was discussed in the previous section of the article concerning the compatibility of Kumaravadivelu's first four principles with content-based instruction, English immersion, and culture-specific ESP teaching. Absolutely the same may be said about the last six principles - they are just as compatible with experiential learning as they are with the three already analyzed approaches - and for the same reasons as explained in the preceding section.

This compatibility means that experiential learning, as a practical methodology unifying into one single entity the three paradigms indicated above, may be just as safely considered to be based on the principles of the principled pragmatic approach as that approach was shown to make a sound foundation for those three paradigms taken separately.

However, this does not mean that principled pragmatism, as the theoretical base for the new unified paradigm of ESP teaching, and experiential learning, as the practical implementation of that paradigm, are simply the sum of the three former ESP paradigms: content-based instruction, English immersion, and culture-specific ESP teaching. If the constituent parts (the three paradigms in our case) joined together really make a new system/new paradigm, this system/paradigm will always be something more than the sum of its parts - which is a basic postulate of the General System Theory (Bertalanffy, 1968). 
We see this new system/new paradigm in constructivism in ESP teaching and learning with principled pragmatism as its theoretical foundation and experiential learning as its practical implementation.

\section{CONSTRUCTIVISM AS A NEW PARADIGM IN ESP TEACHING AND LEARNING}

Constructivism in pedagogy (Glaserfeld, 1995; Richardson, 2003), just the same as experiential learning, was not initially designed for teaching foreign languages and entered that field and made some 'niche' for itself in ESP not earlier than the last decade (Tarnopolsky, 2012). In the constructivist approach to ESP acquisition students acquire the language and communication skills mostly by involuntarily 'self-constructing' them in real-life activities, or activities faithfully modeling a real life situation and conducted in the target language. In this case, students gain command of their language knowledge and communication skills as a by-product of performing their real-life or modeled activities, thus internalizing (appropriating) the knowledge and skills and not consciously learning them or memorizing the language forms. Because of this, we can speak of involuntary/subconscious language acquisition which is much more efficient than conscious learning (Tarnopolsky, 2012). For instance, such an activity as roleplaying in the target language a psychological consultation (a professional psychologist consulting a client) in a class of ESP for students of psychology is a typical constructivist learning activity modeling a real-life professional situation. Students' attention is focused on the subject matter of the situation (psychological consultation) and the language and communication aspects are acquired involuntarily thanks to the fact that the subject matter is processed in the target language and not in the learners' L1.

From the above description and example, it can be clearly seen that the constructivist learning activities and experiential learning activities are identical. So, both of them include content-based instruction, intercultural training, and have target language immersion as their highest point. Just as in experiential learning, constructivist instruction is rooted in principled pragmatism because students' self-constructing of their language knowledge and communication skills requires well-grounded eclectic (principled pragmatic) combination of achievements of different approaches in language teaching if the elements from those diverse approaches are to help learners in self-constructing their target language communication system. For instance, constructivism in language teaching, though being predominately communicative in its orientation, does not preclude using language-focused exercises when they can help involuntary language acquisition (see Tarnopolsky, 2018), though the most extreme forms of the communicative approach do not allow them to be used (Krashen, 1982).

Everything said above allows us to draw the conclusion that constructivism is the most appropriate cover name for the new ESP teaching paradigm that is based on principled pragmatism, implemented in pedagogical practice through experiential learning, and which has as its indispensable components content-based instruction, English immersion, and culture-specific ESP teaching.

However, the paradigm in question is not just the sum of its above-mentioned parts. It is something more than that because, as follows from the definition and description of constructivism at the beginning of this section of the article, none of the separate constituent parts accentuate the most prominent feature of the paradigm as a whole: self-constructing 
by students of their own ESP language and communication system, i.e. developing that system for themselves mostly autonomously (Benson, Voller, 1997; Dam, 2002). None of those separate constituent parts makes this feature prominent, it is only their harmonious unification in one constructivist paradigm that brings it to the forefront, making the paradigm itself unique and innovative.

\section{CONCLUSION}

The new, and even innovative, constructivist paradigm of ESP teaching and learning at tertiary non-linguistic schools has been presented and substantiated in the article. This paradigm unifies into one organic and harmonious whole the three most advanced and cutting-edge of today's ESP teaching and learning paradigms: content-based instruction, English immersion, and culture-specific target language learning.

It is demonstrated that such a unification and even integration of the three paradigms is feasible on the theoretical basis of principled pragmatism with its 10 underlying principles, which, when used in unison, make the presented language teaching approach adequate from the point of view of the latest achievements in developing the most efficient means of target language acquisition. And when those principles are applied for 'welding' together several different approaches, they help avoid discrepancies and achieve their harmonious and 'seamless' unification. As the practical implementation of the new paradigm rooted in principled pragmatism, experiential learning with the kinds of learning activities typical for this methodology is suggested.

It is shown that such a paradigm represents constructivism in ESP teaching and learning and may be called the constructivist paradigm. The constructivist paradigm is not simply the sum of its constituent parts: content-based instruction, English immersion, and culturespecific target language learning joined together by the principled pragmatic approach and experiential learning methodology. As a result of such fusion, a new quality of the novel integrated entity emerges. That quality of the new ESP teaching and learning paradigm, which makes it innovative, is learners' self-construction of their language knowledge and communication skills through mostly autonomous and highly varied learning activities.

The new paradigm has been substantiated not only theoretically. Experimental studies (Tarnopolsky, Momot, Kozhushko, et al., 2008; Tarnopolsky, Kozhushko, Degtiaryova, et al., 2011) have proved that, if practical ESP teaching at tertiary schools is organized on the basis of the new paradigm as described in this article, the students attain far higher learning outcomes, sometimes even surprisingly high, in comparison with the more traditional approaches to ESP teaching and learning. This gave an opportunity to develop a series of constructivist ESP coursebooks for teaching English for professional communication to students of different majors: future economists and business people, psychologists, pedagogues, managers of tourism, students of technology. The list of those coursebooks, which have become widely used and popular in ESP courses at Ukrainian tertiary educational institutions, is given in the Addendum. There is an ample scope for further studies in the direction discussed in the article through spreading and adapting the elaborated constructivist paradigm to different ESP courses taught to university students of various majors. 


\section{REFERENCES}

Benson, P, \& Voller, P. (Eds). (1997). Autonomy and Independence in Language Learning. London and New York: Longman.

Bertalanffy, L. von. (1968). General System Theory: Foundations, Development, Applications. New York: George Braziller.

Brinton, D.M., Snow, M.A., \& Wesche, M.B. (1989). Content-Based Second Language Instruction. New York: Newbury House Publishers.

Burkert, A., Mumford, S., \& Lackman, K. (2010). Symposium on grammar teaching in the post-communicative era. In Briony Beaven (Ed.) IATEFL 2009 Cardiff Conference Selections (pp. 98-100). Canterbury, Kent: IATEFL.

Byram, M. (1997). Teaching and Assessing Intercultural Communicative Competence. Clevedon: Multilingual Matters.

Council of Europe. (2001). Common European Framework of Reference for Languages: Learning, Teaching and Assessment. Strasbourg.

Dam, L. (2002). Plenary: Developing learner autonomy - preparing learners for lifelong learning. In A. Pulverness (Ed.). IATEFL 2002. York Conference Selections (pp. 4152). Whitstable, Kent: IATEFL.

Ferradas, C.M. (2010). Plenary: Outside looking in: intercultural and intermedial encounters in ELT. In Briony Beaven (Ed.) IATEFL 2009 Cardiff Conference Selections (pp. 16-20). Canterbury, Kent: IATEFL.

Fotos, S.S. (1994). Integrating grammar instruction and communicative language use through grammar consciousness-raising tasks. TESOL Quarterly, 28 (2), 323-351.

Glaserfeld, E. von. (1995). A constructivist approach to teaching. In L.P. Steffe, J. Gale (Eds.). Constructivism in Education (pp. 3-16). New Jersey: Lawrence Erlbaum.

Johnson, R.K., Swain, M. (1997). Immersion Education: International Perspectives. Cambridge: Cambridge University Press.

Kessler, C. (Ed.). (1992). Cooperative Language Learning: A Teacher's Resource Book. Englewood Cliffs, NY: Prentice Hall Regents.

Kohonen, V., Jaatinen, R., Kaikkonen, P., Lehtovaara J. (2014). Experiential Learning in Foreign Language Education. New York: Routledge.

Kolb, D. (1984). Experiential Learning: Experience as the Source of Learning and Development. Englewood Cliffs, NJ: Prentice Hall.

Krashen, S.D. (1982). Principles and Practice in Second Language Acquisition. Oxford: Pergamon Press.

Kumaravadivelu, B. (2001). Toward a postmethod pedagogy. TESOL Quarterly, 35 (No.4), 537-560.

Kumaravadivelu, B. (2003). Beyond Methods: Macrostrategies in Language Teaching. New Haven and London: Yale University Press.

Richardson, V. (2003). Constructivist pedagogy. Teachers College Record,105 (9), 16231640.

Robinson, P.C. (1991). ESP Today: A Practitioner's Guide. Hamel, Hempstead: Prentice Hall.

Rogers, C.R. (1983). Freedom to Learn for the 80s. Columbus, OH: Charles E. Merrill Publishing Company.

Rutherford, W.E. (1987). Second Language Grammar. Learning and Teaching. London and New York: Longman. 
Stoller, F.L. (2007). Content-based instruction. In Nelleke van Deusen-Scholl and Nancy H. Hornberger (Eds). Encyclopedia of Language and Education. Vol.4: Second and Foreign Language Education (pp. 59-70). New York, NY: Springer.

Tarnopolsky, O.B., Momot, V.E., Kozhushko, S.P., et al. (2008). Metodika anglojazychnogo pogruzhenija $v$ obuchenii anglijskomu jazyku I special'nym disciplinam studentov jekonomicheskih vuzov (Method of English Immersion in Teaching English and Professional Subjects to Tertiary Students of Economics). Collective monograph under the general supervision and editorship of O.B. Tarnopolskyy, V.E. Momot, and S.P. Kozhushko. Dnepropetrovsk: DUEL (the original is in Russian).

Tarnopolsky, O. (2011). Experiential B.E. teaching/learning: A happy combination of Intercultural and communicative approaches. Business Issues, Issue 78, 7-8.

Tarnopolsky, O.B., Kozhushko, S.P., Degtiaryova U.V., et al. (2011). Metody'ka navchannya anglijs'koyi movy' studentiv-psy'xologiv: monografiya (Methods of Teaching English to Students of Psychology: A Monograph). General and scholarly editor O.B. Tarnopolsky. Dnipropetrovsk: Alfred Nobel University (the original is in Ukrainian).

Tarnopolsky, O. (2012). Constructivist Blended Learning Approach to Teaching English for Specific Purposes. London: Versita.

Tarnopolsky, O. (2018). Principled pragmatism, or well-grounded eclecticism: A new paradigm in teaching English as a foreign language at Ukrainian tertiary schools? Advanced Education, 10, 5-11.

White, R., Arndt, V. (1991). Process Writing. Harlow: Longman.

\section{ADDENDUM}

The list of ESP coursebooks designed on the basis of the constructivist paradigm:

Tarnopolsky, O., Kozhushko, S. (2007). Business Projects. Coursebook. Student's Book and Workbook. Second edition: Revised and Supplemented. Vinnytsa: Nova Knyga.

Tarnopolsky, O., Kozhushko, S., Degtiaryova U., Bespalova, N. (2011). Psychological Matters. A Coursebook of English for Students of Psychology. Student's Book and Workbook. Kyiv: Firma "INKOS."

Tarnopolsky, O., Kornieva, Z., Avsiukevich, U., Zhevaga, V., Degtiaryova, U. (2014). Professional Basics. A Textbook of English for $1^{\text {st }}$ Year Students Majoring in Technology and Economics. Student's Book and Workbook. General and scholarly editors Oleg Tarnopolsky and Zoya Kornieva. Vinnytsa: Nova Knyga.

Tarnopolsky, O., Volkova, N., Kozhushko, S., Miasoid, G., Stojković, N. (2015). Pedagogical Matters. A Coursebook of English for Students of Pedagogy. Student's Book and Workbook. Dnipropetrovsk: Alfred Nobel University.

Tarnopolsky, O., Kozhushko, S., Miasoid, G., Bespalova, N., Medynska, S. (2018). Tourism and Hospitality Industry Matters. Textbook. Dnipro: Alfred Nobel University. 